\title{
Commentary \\ Tight glycaemic control in the intensive care unit: pitfalls in the testing of the concept
}

\author{
Dieter Mesotten
}

Department of Intensive Care Medicine, Catholic University of Leuven, University Hospital Leuven, Herestraat 49, B-3000 Leuven, Belgium

Corresponding author: Dieter Mesotten, dieter.mesotten@med.kuleuven.be

Published: 24 October 2008

Critical Care 2008, 12:187 (doi:10.1186/cc7086)

This article is online at http://ccforum.com/content/12/5/187

(c) 2008 BioMed Central Ltd

See related research by De La Rosa et al., http://ccforum.com/content/12/5/R120

\begin{abstract}
Tight glycaemic control emerged on the scene of critical care in 2001. Surprisingly, not many confirmation trials have been published so far. The randomised controlled trial by De La Rosa and colleagues is a timely and valuable attempt to repeat the landmark Leuven studies. The failure to replicate the beneficial effects of tight glycaemic control may boil down to some less obvious defaults in the set-up of the trial despite a seemingly adequate study design. The incorporation of ample power calculations and strict adherence to glucose targets are essential to fairly compare studies on tight blood glucose control. Only if these basic conditions of study design are fulfilled can the effectiveness of the therapy be assessed.
\end{abstract}

The study of De La Rosa and colleagues [1] is the first published randomised controlled trial set up to test whether tight glycaemic control in a mixed medical-surgical intensive care unit (ICU) population is beneficial. The proof-of-concept work by Van den Berghe and colleagues [2] in Leuven showed, in two separate single-centre studies, that lowering blood glucose levels to 80 to $110 \mathrm{mg} / \mathrm{dL}$ (4.4 to $6.1 \mathrm{mM}$ ), compared with a strategy in which insulinisation is started only when blood glucose levels exceeded $180 \mathrm{mg} / \mathrm{dL}$ (10 mM), improved the outcome in a surgical [2] as well as in a medical [3] ICU patient population. The trial of De La Rosa and colleagues did not confirm the results from these seminal Leuven studies.

To unravel the roots of the discrepancy between the results, the basic principles of evidence-based medicine may be a helpful guide. Foremost, a relevant clinical question leads to the study hypothesis, which ought to be reflected in the study design. In this regard, De La Rosa and colleagues should be congratulated that the question whether tight glycaemic control truly works in a mixed ICU population resulted in a randomised controlled study design. This is a major step-up over implementation studies, which showed a benefit of tight glycaemic control but are substandard to assess effectiveness of a therapy [4]. The overall methodological quality was adequate with regard to randomisation, allocation concealment, intention-to-treat analysis, and completeness of followup. The slight differences in study population, such as the proportion of patients post-cardiac surgery and the onadmission APACHE (Acute Physiology and Chronic Health Evaluation) II score, are probably of minor importance. The pitfalls that matter may hide beneath the surface.

First, the primary outcome in the trial of De La Rosa and colleagues was 28-day mortality. Although this is a clear-cut and hard endpoint, it may not be the most appropriate. As tight glycaemic control is a preventative strategy against ICU complications such as infections, prolonged weaning, and ultimately death, benefit can be expected only if patients remain in the ICU for at least a week. The Kaplan-Meier plots of the hospital survival in the trials of Van den Berghe and colleagues start to diverge only around day 25 and the followup extended well over 100 days. Alternatively, the 90-day mortality, which is being used in the NICE-SUGAR (Normoglycaemia in Intensive Care Evaluation and Survival Using Glucose Algorithm Regulation) multi-centre trial, may have been better [5].

Second, the study was predestined to capsize as the power calculation drew on an unrealistic absolute risk reduction of $10 \%$ in the 28 -day mortality. It is now known from the Leuven studies that at most a $4 \%$ absolute risk reduction in the intention-to-treat population can be expected in the surgical as well as in the medical ICU population [6]. Consequently, the study was already vastly underpowered to start with, aiming to recruit only 504 patients. The combined Leuven population, in hindsight also underpowered in the intention- 
to-treat analysis, included 2,748 patients. To address this issue, the NICE-SUGAR trial has just stopped after having recruited 6,100 patients [5].

Third, further aggravating the problem of power, the study turned out to realize intensive insulin therapy, but without tight glycaemic control. The median morning blood glucose level in the intensive treatment group was $120 \mathrm{mg} / \mathrm{dL}(6.7 \mathrm{mM})$, which is higher than the preset target of 80 to $110 \mathrm{mg} / \mathrm{dL}$ (4.4 to $6.1 \mathrm{mM}$ ). As a result, only $39.4 \%$ of the patients in the intensive treatment groups remained within range for their entire ICU stay, whereas in the Leuven studies this was over $70 \%$. Of minor importance, in the standard group, the authors aimed to maintain blood glucose levels of between 180 to $200 \mathrm{mg} / \mathrm{dL}$ (10 to $11.1 \mathrm{mM}$ ), but expectedly the median morning blood glucose level drifted to $148 \mathrm{mg} / \mathrm{dL}(8.2 \mathrm{mM})$, with only $17.2 \%$ of the patients in range. Such a deviation points to protocol violations or a learning curve in the blood glucose control or a combination of the two. The resulting overlap of about $50 \%$ between the standard and intensive treatment groups weakened the robustness of the results of the study. It also makes it impossible to gauge an effect size, let alone to decisively judge the effectiveness of tight glycaemic control.

The honest conclusion from this study is that tight glycaemic control is a demanding and complex intervention, making it hard to steer blood glucose levels in the right stratum. For these complex interventions, exploratory trials (in this case, the Leuven studies) should be followed by an adequately controlled and powered study to assess replicability and finally by long-term implementation studies, testing effectiveness in uncontrolled settings [7].

To put everything into perspective, it is important to point out that insulin was discovered in 1921. Now, well after 80 years, the scientific and clinical endocrine community is still unsure about the right targets in glycaemic management $[8,9]$. Hence, we ought to be very careful not to thwart the concept of blood glucose control in the critically ill patient before giving it a fair chance in properly executed confirmation trials.

\section{Competing interests}

The author declares that he has no competing interests.

\section{References}

1. De La Rosa GD, Donado JH, Restrepo AH, Quintero AM, Gonzalez LG, Saldarriaga NE, Bedoya MT, Toro JM, Velasquez JB, Valencia $\mathrm{JC}$, Arango CM, Aleman PH, Vasquez EM, Chavarriaga JC, Yepes A, Pulido W, Cadavid CA: Strict glycemic control in patients hospitalized in a mixed medical and surgical intensive care unit: a randomized clinical trial. Crit Care 2008, 12:R120.

2. Van den Berghe G, Wouters P, Weekers F, Verwaest C, Bruyninckx F, Schetz M, Vlasselaers D, Ferdinande P, Lauwers P, Bouillon R: Intensive insulin therapy in the critically ill patients. $N$ Engl J Med 2001, 345:1359-1367.

3. Van den Berghe G, Wilmer A, Hermans G, Meersseman W, Wouters PJ, Milants I, Van Wijngaerden E, Bobbaers H, Bouillon $\mathrm{R}$ : Intensive insulin therapy in the medical ICU. $N$ Engl $J$ Med 2006, 354:449-461.
4. Krinsley JS: Effect of an intensive glucose management protocol on the mortality of critically ill adult patients. Mayo Clin Proc 2004, 79:992-1000.

5. NICE-SUGAR study design [http://www.clinicaltrials.gov/ct2/ show/NCT00220987].

6. Vanhorebeek I, Langouche L, Van den Berghe G: Tight blood glucose control with insulin in the ICU: facts and controversies. Chest 2007, 132:268-278.

7. Campbell M, Fitzpatrick R, Haines A, Kinmonth AL, Sandercock P Spiegelhalter D, Tyrer P: Framework for design and evaluation of complex interventions to improve health. BMJ 2000, 321: 694-696.

8. ADVANCE Collaborative Group, Patel A, MacMahon S, Chalmers J, Neal B, Billot L, Woodward M, Marre M, Cooper M, Glasziou P, Grobbee D, Hamet P, Harrap S, Heller S, Liu L, Mancia G, Mogensen CE, Pan C, Poulter N, Rodgers A, Williams B, Bompoint S, de Galan BE, Joshi R, Travert F: Intensive blood glucose control and vascular outcomes in patients with type 2 diabetes. N Engl J Med 2008, 358:2560-2572.

9. Action to Control Cardiovascular Risk in Diabetes Study Group, Gerstein HC, Miller ME, Byington RP, Goff DC Jr., Bigger JT, Buse JB, Cushman WC, Genuth S, Ismail-Beigi F, Grimm RH Jr., Probstfield JL, Simons-Morton DG, Friedewald WT: Effects of intensive glucose lowering in type 2 diabetes. $N$ Engl J Med 2008, 358:2545-2559. 